\title{
DEVELOPMENT AND CYTOLOGY OF THE ENDOBIOTIC PHASE OF PHYSODERMA PULPOSUM ${ }^{1.2}$
}

\author{
YAMUNA LingaPPa
}

\section{A B S T R A C T}

\begin{abstract}
Lingappa, Yamuna. (U. Michigan, Ann Arbor.) Development and cytology of the endobiotic phase of Physoderma pulposum. Amer. Jour. Bot. 46(4): 233-240. Illus. 1959.-The contents of the zygotes of Physoderma pulposum pass into the epidermal cells of the host and become incipient primary turbinate organs. The latter develop into resting sporangia in 3 different ways: (1) Occasionally, they may become thick walled as sporangia in their entirety. Such monocentric development of the endobiotic thalli is described for the first time in Physoderma; (2) usually, however, the contents of primary turbinate organs undergo centripetal cleavage; or (3) their contents may be cleaved tangentially. As a result, several uni- or multinucleate segments are formed which give rise to tenuous hyphae. The swollen distal end of each tenuous hypha develops into a secondary turbinate organ which in turn gives rise to hyphae and tertiary turbinate organs. Thus, the polycentric organization of the rhizomycelium is maintained. During this process, buds, which develop in the axils of the apical tufts of haustoria of turbinate organs, enlarge into resting sporangia. Nuclear divisions in turbinate organs and of resting sporangial inilials are mitotic, and 4 chromosomes are evident on the equator of the intranuclear spindles. As the resting sporangia are inoperculate, the endosporangia protrude through irregular openings in the exospores.
\end{abstract}

IN PHYSODERMA PULPOSUM sexuality is expressed by isogametes, derived from different epibiotic sporangia, which fuse in pairs and give rise to zygotes (Lingappa, 1958). The present contribution concerns the development of zygotes in the host tissues. In 1940, Sparrow suggested that in Physoderma planospores from epibiotic sporangia might function as gametes and fuse and that the resulting zygotes might initiate the endobiotic resting sporangial phase. In spite of numerous studies of several species of Physoderma (cf. Karling, 1950), the origin of the endobiotic phase was not precisely known in any species, and Sparrow's hypothesis was not experimentally proved. This was due to lack of evidence from controlled infection experiments using proper inocula. Previous studies in Physoderma were based entirely on infected host plants collected from the field. Such materials are unsuitable for determinative studies because the origin and sequence of developmental stages of infection cannot be traced with certainty in such material. Therefore, the following observations are based on studies of living as well as fixed and stained materials which were obtained, at desired intervals, after inoculation and infection of host plants in the greenhouse.

Material and Methods.-This study was made

${ }^{1}$ Received for publication January 28, 1958.

2 Portion of a Ph. D. thesis submitted to the Graduate School, Purdue University, Lafayette, Indiana. The author is ever grateful to her major professor, Dr. J. S. Karling, for guidance and encouragement during the present investigation, and help in preparation of the manuscript. The work was supported by a Cancer Research Fellowship of the Indiana Elk's Association. under greenhouse and laboratory conditions and the methods of inoculation, sampling, fixing and staining of infected tissues, and of obtaining germination of epibiotic and resting sporangia were the same as described previously (Lingappa, 1959). In this study, however, the inocula contained a large number of zygotes and copulating gametes. Host plants inoculated with planospores derived from single epibiotic sporangia, or those from germinating resting sporangia, developed only epibiotic sporangia. It was found that the planospores from single epibiotic sporangia or those from germinating resting sporangia do not copulate. It was also determined that the gametes copulated in large numbers if derived from over-ripe epibiotic sporangia, i.e. those that were retained on the host plants in the greenhouse, or stored in closed containers at $10^{\circ} \mathrm{C}$., for over 3 days after maturity. Therefore, gametes from several over-ripe but viable epibiotic sporangia were used as inocula. They were examined, prior to using them, for the presence and abundance of copulating gametes and zygotes. However, not all planospores in such inocula function as gametes and copulate. Consequently, zygotes as well as planospores (zoospores and unfused gametes) infect the host cells. Infection was studied microscopically. As the infecting planospore remains on the host cell, whereas the infecting zygote enters into the host cell (fig. 9), they were easily distinguishable. The course of development of the zygote is the same in Chenopodium album $\mathrm{L}$. as in Atriplex patula L. when inoculated with P. pulposum from the respective hosts. The following account relates to the development of the endobiotic

|The Journal for March (46: 145-232) was issued March 16, 1959] American Journal of Botany, Vol. 46, No. 4, April, 1959. 

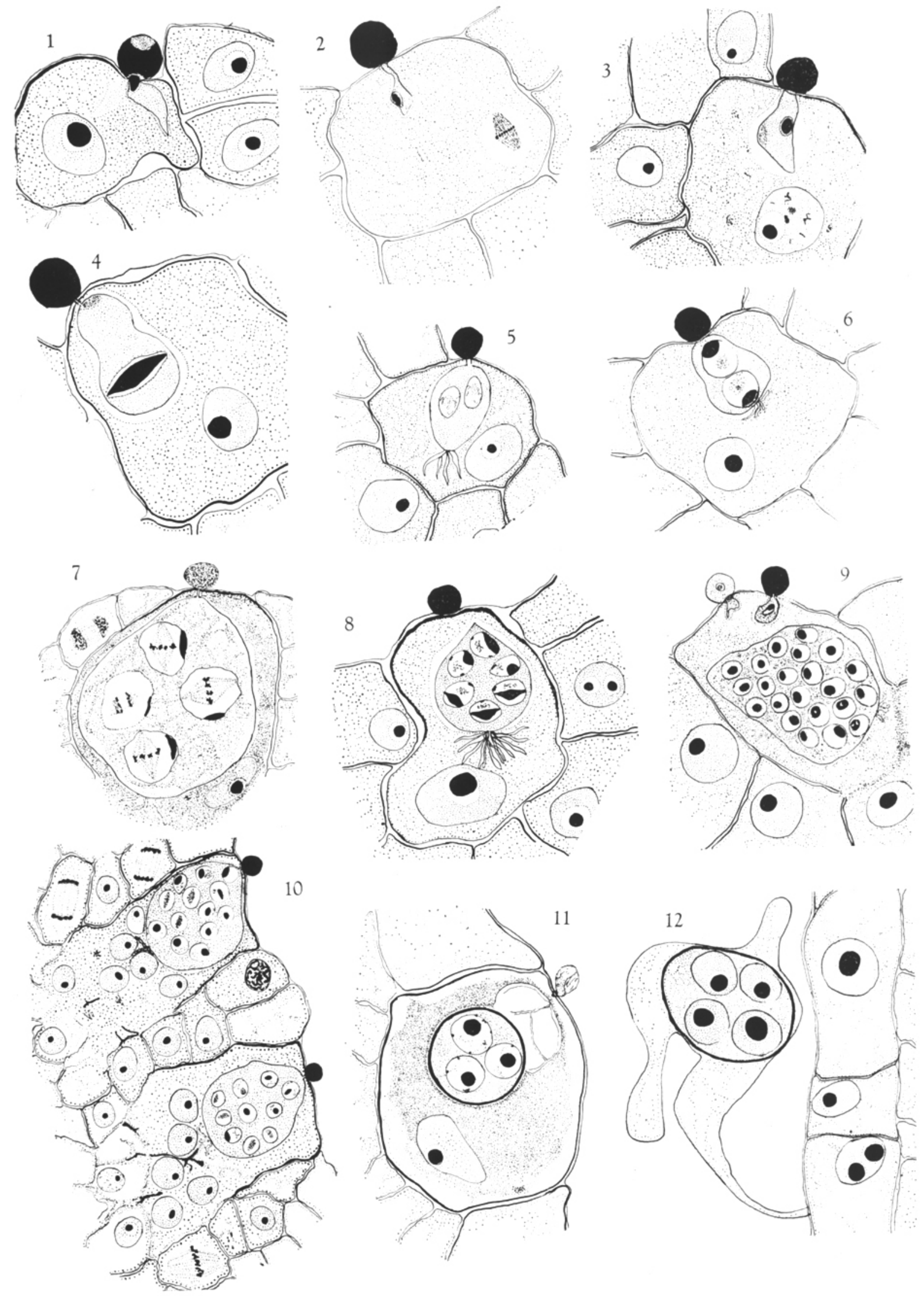
phase under greenhouse conditions, at temperatures between $20^{\circ}$ to $30^{\circ} \mathrm{C}$.

ObSERVATIONS.-Development of the primary turbinate organs.- The zygotes settle on the host and germinate as described for planospores (Lingappa, 1959). The narrow infection or germ tubes penetrate the epidermal cells and continue to grow (fig. $1,2)$. In stained sections, the entire body of the zygote stains deeply with safranin or crystal violet, whereas the infecting planospores stain differentially. The contents of the zygote flow into the growing infection tube, and the parasite becomes intracellular. Consequently, even on the first day of infection, the zygote body appears as an empty button on the host surface in contrast to the lightstaining infecting planospores (fig. 9). Inside the epidermal cells, the 2-day-old parasite is sac-like with an irregular outline (fig. 4). The outer membrane of the zygote remains attached to the host surface for about 5 days after infection (fig. 1-11), and it may be connected to the thallus by the remnants of the infection tube (fig. $4,5,7$ ). Inasmuch as the intracellular thalli mature into primary turbinate organs and initiate the endobiotic phase, they are called incipient turbinate organs. During the early development of the zygote, the center of growth and organization passes from the zygote body into the intracellular infection tube which is the rudiment of the rhizomycelium. Accordingly, from the beginning, the development of the zygote is different from that of the planospores; in the latter, the center of growth and organization remains in the epibiotic planospore body (Lingappa, 1959).

Within $48 \mathrm{hr}$. after infection, the incipient primary turbinate organ measures 3-5 $\times 6-10 \mu$ (average of 30 turbinate organs) and contains granular protoplasm and the zygote nucleus (fig. $3,4)$. Divisions of such primary nuclei have not been observed, but they apparently occur in the 2-day-old incipient turbinate organs, because most 3-day-old turbinate organs are binucleate (fig. 5, 6). By the fifth day, the thalli are 14-40 × $12-$ $50 \mu$ (average of 70 turbinate organs), subglobose, ovoid, oblong, or pyriform, and multinucleate (fig. $7-10)$. In the meantime, a tuft of blunt haustoria is evident at the apex of each turbinate organ (fig. 5-10, 14). A pparently, these haustoria develop on the second or third day following infection, but are clearly visible only after the fourth day. Unlike the bushy rhizoids of the epibiotic sporangia, the haustoria are unbranched and fewer. They degenerate when the tenuous hyphae develop from the turbinate organs.

Concomitant with the development of the incipient turbinate organ, the host cell enlarges (fig. 1-6, 11), and the host protoplasm increases in amount and density (fig. 7). The host nucleus enlarges and may divide (fig. 2), but no evidence was obtained that this is followed by the division of the host cell. By the time the incipient turbinate organs have become multinucleate, the lower walls of the host cells as well as the walls of the adjacent cells lyse (fig. 9, 10). The protoplasm of the host cells whose walls have been lysed by the action of the fungus fuse to form a multinucleate mass or symplast, a term proposed by Hanstein (1880) for such a structure and later used by Kusano (1907) to describe a similar host reaction to infection by $S y n$ chytrium. Consequent to dissolution of host cell walls, incipient turbinate organs lie in the dense symplast which includes several hypertrophied host nuclei (fig. 10). This complex of naked symplast and the turbinate organs can be tessed out from the fresh galls en masse, and might be easily mistaken for a plasmodium. Although the turbinate organs are enveloped by the host cell contents, or by the symplast throughout their development, a clear area is visible between the two surfaces (fig. 3-8). Inasmuch as the incipient turbinate organs are enveloped by definite membranes from the start, and the density of their contents differs from that of the surrounding host cytoplasm, they are distinguishable even in fresh mounts. Nevertheless, details of development of rhizomycelia are difficult to follow in temporary preparations. However, growth of the turbinate organs into rhizomrcelia can be observed clearly in fixed and stained serial sections.

The primary turbinate organs attain maturity when 5- or 6-davs old and give rise to resting sporangia in 3 different ways, namely, by monocentric development into resting sporangia, by polycentric development into rhizomycelia from centripetally cleaved turbinate organs, and by polycentric derelonment into rhizomycelia from tangentially cleaved turbinate organs.

Fig. 1-12. Development of the endobiotic phase of Physoderma pulposum in Chenopodium album L.-Fig. 1. Infection by zygote. $\times 1500$. - Fig. 2 . Swollen infection tube; nucleus of the host cell is dividing. $\times 1500 .-F i g .3$. One-day-old primary turbinate organ, in a clear pocket in the host protoplasm. $\times 1250$. Fig. 4. Two-day-old primary turbinate organ. $\times 1500$.-Fig. 5, 6. Three-day-old primary turbinate organs; apical tufts of haustoria have developed. $\times 1000, \times 1250$, respectively.-Fig. 7. Nuclear divisions in 4-day-old turbinate organ; note the dense host protoplasm around it; nucleus of neighboring host cell is dividing. $\times 2000,-$ Fig. 8 . Four-day-old turbinate organ; nuclei appear to be in prophase. $\times 1300$-Fig. 9. Five-day-old turbinate organ; host cell walls are lysing; zoospore and zygote infecting the same host cell (host was reinoculated 4 days after first inoculation). $\times 1000 .-F i g .10$. Two 5-day-old primary turbinate organs; development of the gall and lysigenous cavity are in progress. $\times 800 .-F i g .11$. Development of a single resting sporangium from a primary turbinate organ. The latter appears as shrivelled structure. It occurred in an epidermal cell of Atriplex patula L., cross infected with $P$. pulposum on $C$. album; 1-week-old. X1500.-Fig. 12. Primary turbinate organ has developed into a single resting sporangium in an epidermal hair of C. album; l-week-old. $\times 2000$. 


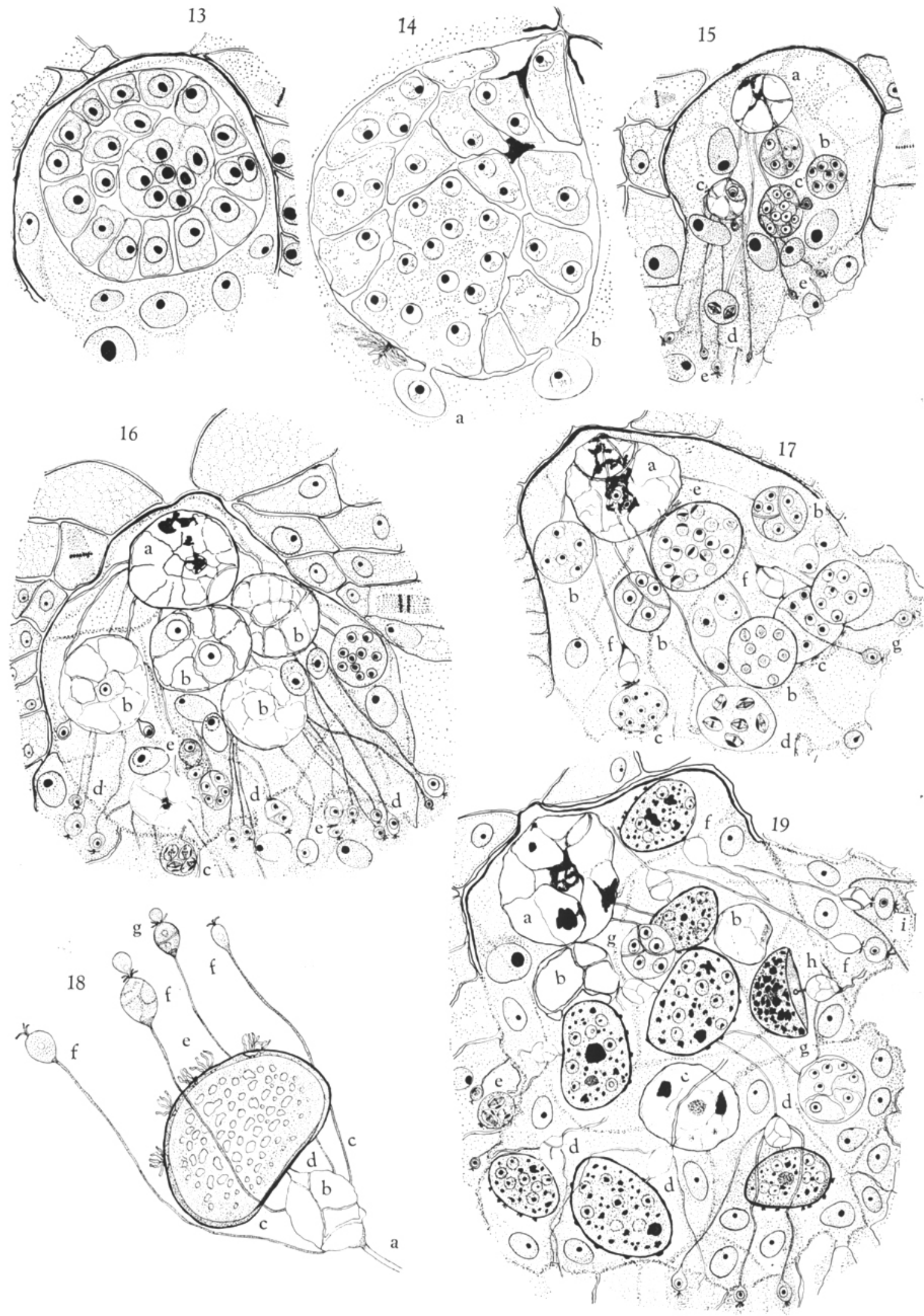


Monocentric development of the primary turbinate organs.-The mature primary turbinate organ may develop a thick wall and directly become a resting sporangium (fig. 12); or its content may flow out into a bud-like outgrowth and the latter develop into a resting sporangium (fig. 11). Such monocentric development occurs commonly in epidermal hairs of host plants (fig. 12) and in epidermal cells of resistant or unfavorable hosts, such as in $A$. patula inoculated with $P$. pulposum on C. album (fig. 11) and vice versa. In either case, typical symptoms are not produced on the hosts. Apparently, this is a precocious development of the primary turbinate organs brought about by unfavorable conditions in such host cells. Although moncentric development of the endobiotic phase is uncommon, it is of special interest because it is here recorded for the first time in Physoderma. However, if careful studies were to be made, monocentric development of endobiotic thalli might be found in other Physoderma species also.

Polycentric rhizomyceloid development of the endobiotic thalli from centripetally-cleaved turbinate organs.- The endobiotic phase is predominantly polycentric, and a single turbinate organ is able to produce, by succession, numerous resting sporangia. This is brought about by the growth of successive turbinate organs from primary ones. In $P$. pulposum, the prevailing method of origin of the polycentric organization is as follows: the multinucleate contents of the mature primary turbinate organs cleave into several polyhedral segments (fig. $13,14)$. The cleavage planes develop centripetally, so that the central mass is cleaved last (fig. 13), a type of development described for the first time in Physoderma. The segments are uni- or multinucleate, and their size, shape, number and arrangement vary considerably. However, they are enclosed by the common delicate walls of the turbinate organs, and in this condition (fig. 13, 14) most of the 5-day-old primary turbinate organs resemble the sporangiosori of Synchytrium. From each segment, one or more protuberances or buds develop, and the contents of the segments pass into the latter through narrow connecting tubes (fig. $14 a, b)$. As far as it is known, only a single nucleus enters a bud and, apparently, the segments produce as many buds as there are nuclei. After development of buds, the empty turbinate organs shrivel (fig. 15a, 16a, 17a, 19a), degenerate and disappear later. Occasionally, a segment or a portion of its contents may remain in the turbinate organ, without developing buds, and these degenerate (fig. 17a).

The tubular proximal portions of the buds elongate into tenuous hyphae which are swollen terminally. These terminal swellings are the incipient secondary turbinate organs, and each contains a nucleus and bears an apical tuft of 3-5 unbranched haustoria. The hyphae penetrate the host cells adjoining the lysigenous cavity and lyse their walls. Consequently, all the secondary turbinate organs develop within lysigenous cavities, and the rhizomycelia are no longer intracellular. Penetration of host cells by the tenuous hyphae and development of rhizomycelia are illustrated by the tertiary and quarternary turbinate organs in fig. 15-19; their development is similar to that of the primary turbinate organs. As the incipient secondary turbinate organs enlarge, their nuclei divide mitotically, and their contents again centripetally cleave into polyhedral segments (fig. 15c, 16b). From the latter, the tenuous hyphae and tertiary turbinate organs develop as described for the secondary turbinate organs. By this process, the subsequent orders of turbinate organs are formed, and the polycentric organization is reduplicated into an extensive rhizomycelium. However, it was noted that buds which develop in the axils of the apical tufts of haustoria enlarge into resting sporangia. They develop close to the empty turbinate organs, because the connecting tubes do not elongate (fig. 17c,e; 18e, 19d,f,h). Such resting sporangial initials are invariably produced by the quarternary and higher orders of turbinate organs. As far as it is known, a single resting sporangium develops from a turbinate organ,

Fig. 13-19. Development of the endobiotic phase of Physoterma pulposum in Chenopodium album.-Fig. 13. Five-dayold primary turbinate organ showing centripetal cleavage. $\times 2000$. - Fig. 14. Development of uninucleate buds (a, b) from segments. $\times 2000$. - Fig. 15. Six-day-old rhizomycelium with primary $(a)$, secondary (b, d) and tertiary (c, e) turbinate organs. $\times 1200 .-F i g .16$. Eight-day-old rhizomycelium in a stem gall with empty primary (a) and secondary (b), and young tertiary (d) turbinate organs and incipient resting sporangium (e). Mitosis in teritary turbinate organ (C). $\times 500$. -Fig. 17. Eight-day-old rhizomycelium in a leaf gall with empty primary (a), tangentially cleaved secondary (b) turbinate organs, and young resting sporangia ( $c, e)$. Mitosis in secondary turbinate organ (d). Apical buds and lateral tenuous hyphae are developing from secondary turbinate organs (f), the former develop into resting sporangia (c) and the latter into tertiary turbinate organs $(\mathrm{g})$. Note early appearance of resting sporangia as compared to Fig. 17 of the same age. $\times 50 .-F i g .18$. Predominent type of reduplication of rhizomycelium. Segmented turbinate organ (b) is borne on hypha (a). Lateral tenuous hyphae (c) bear incipient turbinate organs (f). Narow connecting tube (d). Circlet of haustorial tufts on the resting sporangium (e). Incipient resting sporangia ( $\mathrm{g}$ ). (Drawn from lactophenol-Cotton blue mount of a dissected 7-day-old gall). $\times 750$. - Fig. 19. Nine-day organs: primary (a), secondary (b), tertiary (c) and quarternary (d). Note the decrease in size and septation of the higher orders of turbinate organs and some quarternary (f) ones are unsegmented; resting sporangia develop from the latter (f) only. Segmented turbinate organs $(\mathrm{g})$. Central pit in the resting sporangium and tube connecting it with the empty turbinate organ (h). $\times 500$. 

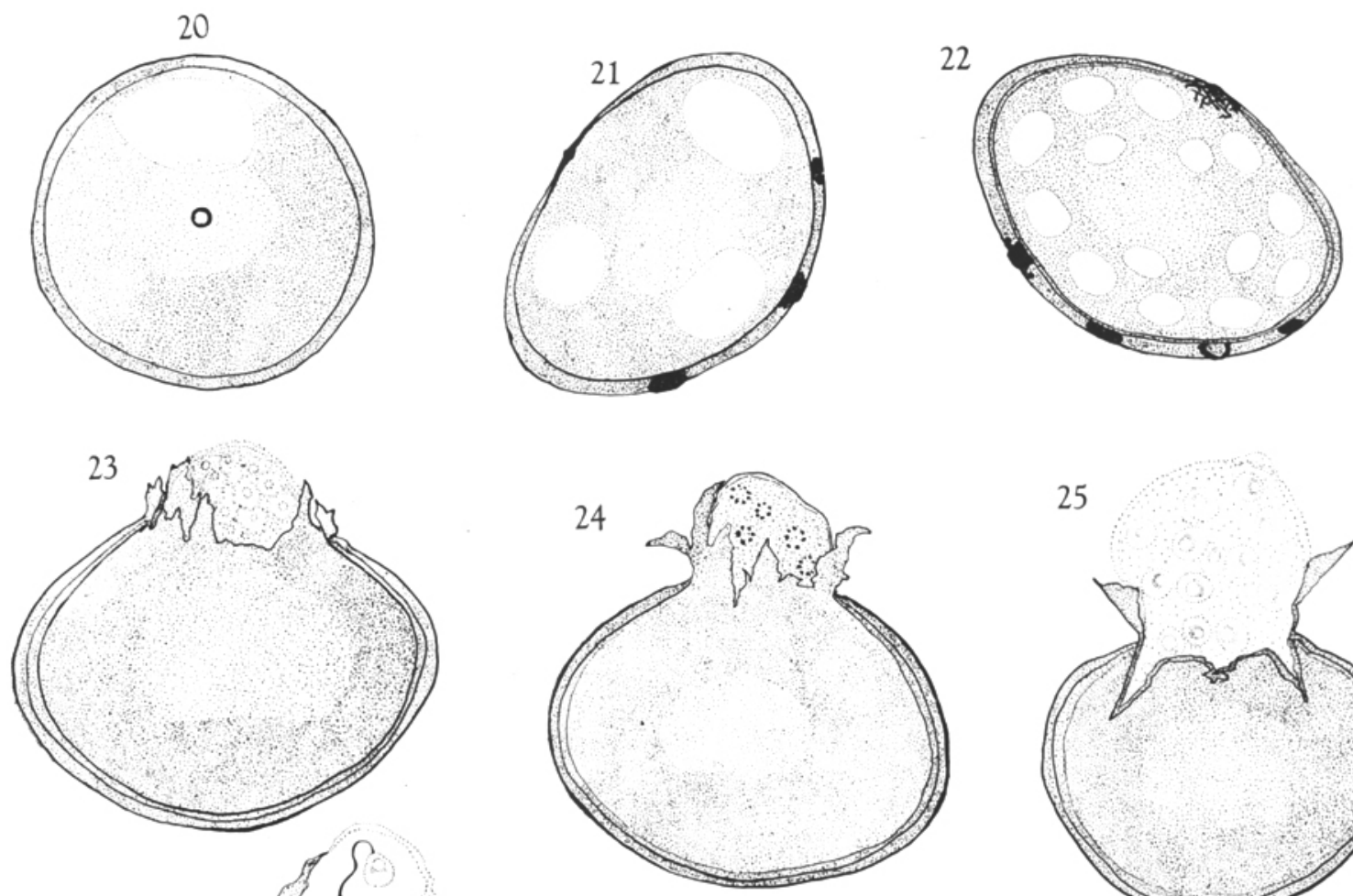

\section{5}
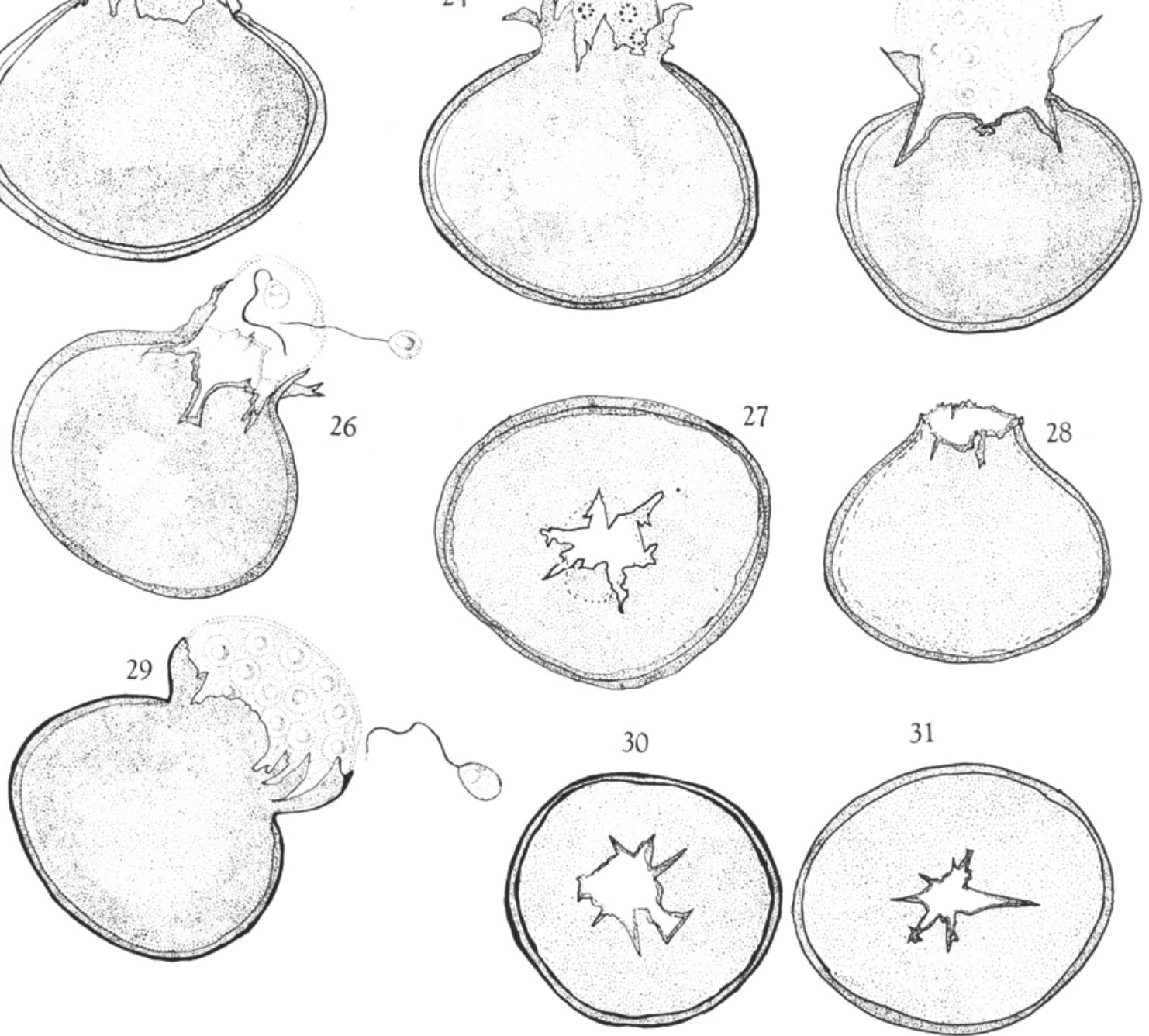

Fig. 20-31. Germination of resting sporangia of Physoderma species.-Fig. 20-28. P. Pulposum.-Fig. 20. Resting sporangium, showing the central pit. $\times 1000$. Fig. 21. Scars left by haustoria. $\times 1000 .-$ Fig. 22 . Exospore is cracking around the central pit. $\times 1000$.-Fig. 23-25. Development of endosporangia. $\times 1000 .-$ Fig. 26. Discharge of planospores. $\times 700 .-F i g$ 27, 28. Empty resting sporangia, showing openings. $\times 1000 .-F i g .29$. Germinating resting sporangium of Physoderma sp. on clover from Australia. $\times 1000 .-$ Fig. 30, 31. Empty resting sporangia of Physoderma sp. on clover and of $P$. hemisphericum on Carum carvi, respectively, showing the openings. 
and the latter may or may not produce tenuous hyphae in addition to a resting sporangium (fig. $19 \mathrm{~d}, \mathrm{f})$. In $P$. pulposum, the tenuous hyphae are less than $80 \mu$ long and $2 \mu$ broad, unbranched, nonseptate, and without the rhizoid-like branches described for Cladochytrium replicatum (Karling, 1937). Also, the incipient turbinate organs are not intercalary but terminal. Characteristically, primary and secondary turbinate organs produce only tenuous hyphae (fig. 15a, 16a,b), whereas tertiary and quarternary turbinate organs produce both tenuous hyphae and resting sporangia (fig. 17f, 19d). However, in the second week after infection, most of the higher orders of turbinate organs produce only resting sporangia (fig. 19f). At that stage, the turbinate organs are $5-10 \mu$ in diameter, remain uninucleate and each produces a single resting sporangium. As tenuous hyphae are not produced from such turbinate organs, further spread of the rhizomycelium comes to an end.

Polycentric rhizomyceloid development of the endobiotic thalli from tangentially-cleaved turbinate organs.-In $P$. pulposum, the contents of the turbinate. organs may cleave tangentially into uni- or multinucleate segments (fig. 17b.f; 18f; 19b,d), as descrited previouslv in $P$. alfalfae (Jones and Drechsler, 1920). Tenuous hyphae, turbinate organs and resting sporangia develop from such turbinate organs in the same manner as described above. Usually, the primary turbinate organs of $P$. pulposum measure $20-50 \mu$ wide, while the subsequent orders of turbinate organs are $5-20 \mu$ in greatest width. Tangential cleavage occurs in turbinate organs smaller than $20 \mu$, and therefore, in those of secondary and higher orders (fig. 17b,f; 18f; 19d). The evidence, however, is not adequate to consider this tvpe of development as different from the type 2 discussed above. Nevertheless, only tangential cleavage has been described for $P$. alfalfae, and whether or not it occurs in other species is not definitely known. Therefore, it is described here separately.

Nuclear division in the turbinate organs and resting sporangial initials.-Turbinate organs of all orders as well as buds which become resting sporangia are initially uninucleate and become multinucleate as they mature. Divisions of these "primary" nuclei have not been observed. Divisions of the secondary nuclei are mitotic, with intranuclear spindles (fig. 7, 15d, 16c, 17d, 19e) and are strikingly similar to those described by Karling (1937) in Cladochytrium replicatum. In such divisions, the nuclear membrane is clearly defined and the nucleolus lies at one side of the nuclear cavity as a lens- or disc-shaped, deep-staining body (fig. 7, 8). The spindle extends the full length of the nuclear cavity and its poles appear to be anchored on the nuclear membrane. At metaphase, 4 oval chromosomes are evident on the, equator of the spindle (fig. 7). It is noteworthy that the nuclei here, unlike those of the epibiotic sporangia, do not diminish progressively in size with successive divisions, but remain approximately $4-5 \mu$ in diameter. Previously, Karling (1950) and Gopalkrishnan (1951) reported similar intranuclear divisions in $P$. pluriannulatum and $P$. graminis, respectively. No evidence of amitoses, such as those reported by Jones and Drechsler (1920) in P. alfalfae, has been found. Meiosis has not been observed, and it is not known whether it occurs during the divisions of the primary nuclei, in the primary turbinate organs, or during germination of the resting sporangia.

Development and germination of resting sporangia.-As pointed out above, axillary buds of apical tufts of haustoria of turbinate organs develop into resting sporangia $(17 \mathrm{c}, \mathrm{e} ; 18 \mathrm{~g})$. The buds are uninucleate but become multinucleate as they enlarge, and the resting sporangia contain about 30 nuclei (fig. 17e,c; 19d,f). The wall of the resting sporangia consists of a thick, amber-brown outer layer and a thin, hyaline inner laver, the so-called exospore and endospore, respectively. Resting sporangia have 5 -8 tufts of blunt, deep-seated haustoria which are arranged in a circle (fig. 18e). The haustoria degenerate after the exospores become thickened and leave behind pits or scars (fig. 21, 22 ). As the resting sporangia mature, large numbers of refractive globules accumulate (fig. 18), and in stained preparations, deep-staining materials obscure the nuclei (fig. 19h). The resting sporangia are subspherical, plano-convex, burnt-orange and measure $26-50 \times 28-55 \mu$ (average of 100 sporangia: $39 \times 42 \mu$ ). The empty, hyaline turbinate organs are attached to the resting sporangia but disintegrate later and leave a prominent scar, called here the central pit, in the exospore (fig. 19h, 20). The empty turbinate organs and the connecting tubes were interpreted by Schroeter (1882) as male gametangia and conjugation tubes, respectively, and, therefore, he concluded that the resting sporangia of $P$. pulposum originated by the fusion of 2 cells.

The resting sporangia have been germinated at intervals, 4 months to 4 years after maturity. Sporangia collected in May, 1955 were germinated in August, 1955 and in March, 1958. At $20^{\circ} \mathrm{C}$., nearly $70 \%$ of them germinated in 2 weeks without pretreatments. They did not germinate at $30^{\circ} \mathrm{C}$. and lost viability upon exposure to $60^{\circ} \mathrm{C}$. for $1 \mathrm{hr}$.

Prior to germination, the large refractive globules in the protoplasm break into numerous smaller globules which are uniformly distributed (fig. 20-23). At the same time, the hyaline endospore becomes thicker and clearly visible. Then, the e-ospore begins to crack irregularly from the central pit in all directions (fig. 22). The expanding endosporangium then bulges through the fissures (fig. 23-25). The highly dispersed refractive material in the cytoplasm aggregates to form a limited number of refractive globules, and the protoplasm 
cleaves into spore primordia. The planospores swarm within the endosporangium for more than $1 \mathrm{hr}$. before being discharged. Prior to this, a small papillum develops on the endosporangium (fig. 25), and, as it deliquesces, the planospores escape (fig. 26) one by one, and swim away. No lid or operculum is pushed off from the germinating resting sporangia of $P$. pulposum. (fig. 27, 28). This has been found to be true of Physoderma sp. on clover (fig. 29) from Australia, and P. hemisphericum (fig. 30,31 ) on Carum carvi.

Discussion.-The present study shows that the structure and development of the rhizomycelia of $P$. pulposum are very similar to those described for $P$. alfalfae (Jones and Drechsler, 1920; Line, 1921), but some notew orthy differences were observed. Of these, the monocentric development of the endobiotic thalli and the centripetal cleavage of the contents of the turbinate organs are recorded for the first time in Physoderma. Also, the zygotic origin of the rhizomycelia and resting sporangia indicate that they are diploid. However, meiosis has not been observed, and it is not certain at what stage it occurs. Nevertheless, the fact that the resting sporangia, which contain about 30 nuclei, give rise to twice or more that number of planospores, indicates that the nuclei divide in the germinating resting sporangia; and the divisions might be meiotic. Observations of the author $(1958,1959)$ that planospores develop into epibiotic sporangia and zygotes into the endobiotic phase, confirm Sparrow's (1940) hypothesis. Thus, $P$. pulposum has alternating haploid epibiotic and diploid endobiotic phases. It is quite possible, however, that microcyclic Physoderma species might exist which may lack the repeating epibiotic sporangial phases. In such cases, either sexuality might be lacking altogether, or planospores from germinating resting sporangia might function only as gametes. In view of such possibilities, nothing definite can be said, in general, about the origin of endobiotic phase unless more Physoderma species are intensively studied.

No evidence of a plasmodial stage has been found in the endobiotic phase of $P$. pulposum. According to Vuillemin (1897), the endobiotic phases of this and other Physoderma species consist of granular multinucleate plasmodia, with bundles of musculiform striated fibrils (?), which corrode and perforate the host cell walls. Furthermore, Wilson (1920) in P. alfalfae and recently Bernstein (1957) in $P$. leproides reported the occurrences of endobiotic plasmodial stages. The present observations indicate that they might have misinterpreted the large masses of naked host symplast, which completely envelop the rhizomycelia, as plasmodia. The dense symplasts, which contain numerous hypertro. phied host nuclei and rhizomycelia, can be teased out of 1-week-old galls and resemble giant plasmodia. Also, the incipient primary turbinate organs collapse in improperly fixed and processed preparations and simulate plasmodia.

Dfpartment of Botany
University of Michigan
Ann Arbor, Michigan

\section{LITERATURE CITED}

Bernstein, R. 1957. Studies on the life history of Physoderma leproides (Trabut non $P$. leproides Lagerheim) (= Urophlyctis leproides [Trab.] Magn.). Bull. Res. Counc. of Israel 6: 46-52.

Gopalkrishnan, K. S. 1951. Development and parasitism of Physoderma graminis (Büs.) Fischer, on Agropyron repens (L.) Beauv. Phytopath. 41: 1065-1076.

Hanstein, J. V. 1880. Das protoplasma als Träger der pflanzlichen und thierischen lebensverrichtungen. Heidelberg.

Jones, F. R., and C. Drechsler. 1920. Crownwart of alfalfa caused by Urophlyctis alfalfae. Jour. Agric. Res. 20: 295-324.

Karlinc, J. S. 1937. The cytology of the Chytridiales, with special reference to Cladochytrium replicatum. Mem. Torrey Bot. Club 19: 1-89.

- 1950. The genus Physoderma (Chytridiales). Lloydia 13: 1-71.

Kusano, S. 1907. On the cytology of Synchytrium. Centralblatt f. Bakt. Paristenk. II. 19: 538-543.

LINE, J. 1921. A note on the biology of the "crown gall" fungus of lucerne. Proc. Cambridge Phil. Soc. 20: $360-365$.

Lingappa, Y. 1958. Physoderma pulposum. Mycologia 50: 80-84.

1959. The development and cytology of the epibiotic phase of Physoderma pulposum. Amer. Jour. Bot. 46: $145-150$.

Schroeter, J. 1882. Untersuchungen der Pilzgattung Physoderma. Jahresb. Schles. Vaterland. Cultur. 60: 198200.

Sparrow, F. K., Jr. 1940. Chytridaceous fungi in relation to disease in flowering plants, with special reference to Physoderma. In Abstracts of communications, Third Internat. Congress for Microbiology, New York.

Vuillemin, P. 1897. Sur l'appareil nourricier do Cladochy. trium pulposum. Compt. Rend. Acad. Sci. Paris. 124: 905-907.

Wilson, O. T. 1920. Crown gall of alfalfa. Bot. Gaz. 70: $51-68$. 